\title{
SENSACIONES, SONIDOS Y SILENCIOS EN EL RUIDO DE LAS COSAS AL CAER DE JUAN GABRIEL VÁSQUEZ
}

\author{
Rita De Maeseneer \\ Universiteit Antwerpen \\ Amberes, Bélgica \\ rita.demaeseneer@uantwerpen.be \\ Jasper Vervaeke \\ Universiteit Antwerpen \\ Amberes, Bélgica \\ jasper.vervaeke@uantwerpen.be
}

RESUMEN / ABSTRACT

En El ruido de las cosas al caer (2011) del colombiano Juan Gabriel Vásquez abundan las referencias a las sensaciones, los sonidos y los silencios. En este artículo mostraremos que el énfasis en las percepciones sensoriales y, más en particular, las modalidades de la audición, están estrechamente vinculados al desgarrador rescate del pasado y reflejan una profunda conciencia de los límites del lenguaje. Basaremos nuestro análisis en tres aproximaciones frecuentes en los sound studies. Primero, estudiaremos la intervención de la memoria visual y auditiva en el acto de recordar. Segundo, comprobaremos cómo tanto los sonidos y ruidos mecánicos como la musicalidad poética contribuyen a activar el proceso de la memoria y a crear ecos entre el pasado y el presente. En tercer lugar, nos concentraremos en las implicaciones ontológicas del silencio, lo contrario del sonido.

Palabras clave: Juan Gabriel Vásquez, El ruido de las cosas al caer, percepciones sensoriales, sound studies, literatura colombiana.

SENSATIONS, SOUNDS, AND SILENCE

in the Sound of Things Falling by Juan Gabriel Vásquez

In The Sound of Things Falling (2011) by Colombian Juan Gabriel Vásquez references to senses, sounds, and silences abound. We argue that this emphasis on sensory perceptions 
and specifically on aural expressions is closely linked to the painful recovery of the past and reflects a profound consciousness of the limitations of language to reconstruct memory. In order to substantiate our argument, we discuss three approaches frequently commented on in sound studies. First, we analyze the role that visual and auditory memory plays in the act of remembering. Secondly, we demonstrate how different aural forms such as mechanical sounds and noises and poetical musicality, contribute to activate the processes of recalling the past or to create echoes between past and present. Thirdly, we concentrate on silence, the opposite of sound, in its ontological implications.

KEYWORDS: Juan Gabriel Vásquez, The Sound of Things Falling, sensory perceptions, sound studies, Colombian literature.

Recepción: 29/07/2018

Aprobación: 06/08/2018

\section{INTRODUCCIÓN}

Gracias a sus novelas Los informantes (2004), Historia secreta de Costaguana (2007), El ruido de las cosas al caer (2011), Las reputaciones (2013) y La forma de las ruinas (2015), el colombiano Juan Gabriel Vásquez (Bogotá, 1973) ha ido ganándose un lugar prominente en el corpus de la narrativa latinoamericana contemporánea. Mediante sus ensayos, recopilados en El arte de la distorsión (2009) y Viajes con un mapa en blanco (2018), y la columna que mantuvo entre 2007 y 2014 en el periódico colombiano El Espectador logró convertirse, además, en uno de los intelectuales más destacados de su generación. Sin duda, el estreno de El ruido de las cosas al caer fue crucial en el proceso de consagración literaria de Vásquez. Es por esa novela por la que recibió, en 2011, el Premio Alfaguara de Novela, su primer galardón importante en términos de prestigio, proyección internacional y cuantía económica. En los años siguientes continuó cosechando premios literarios para las traducciones de El ruido: El Prix Roger Caillois (2012), el English Pen Award (2012), el Premio Gregor von Rezzori (2013) y el International IMPAC Dublin Literary Award (2014).

Así las cosas, no sorprende que la obra de Vásquez sea objeto de cada vez más estudios ${ }^{1}$. En lo que se refiere a El ruido de las cosas al caer, la mayoría

\footnotetext{
Son recomendables, entre otros acercamientos académicos, los análisis de: Quesada, sobre la obra temprana de Vásquez; De Hollanda y Giraldo, sobre Los informantes; Montoya y Semilla Durán, sobre Historia secreta de Costaguana; González González, sobre El ruido, Las reputaciones y La forma de las ruinas. Sobre el conjunto de la obra de Vásquez caben
} 
de los acercamientos académicos abordan la novela desde la temática de la narcoviolencia, posicionándola frente a su trasfondo sociohistórico -el auge del tráfico de drogas en los años setenta y el apogeo del narcoterrorismo entre los ochenta y principios de los noventa- y a su contexto literario y periodístico. Así, por ejemplo, varios críticos destacan el hecho de que Vásquez, en vez de focalizar en los perpetradores de la violencia, como han venido haciéndolo los medios de comunicación sensacionalistas y los escritores de las novelas sicarescas, cuente desde la perspectiva de las víctimas colaterales (De Hollanda; Fonseca; Pérez Sepúlveda; Díaz Sedano). Efectivamente, Vásquez “enfrenta los miedos y consecuencias del narcotráfico" (Fonseca 80) en la sociedad colombiana post-Escobar a partir del narrador Antonio Yammara quien reconstruye sus propias vivencias y las del extraficante de drogas Ricardo Valverde. Como suele ser frecuente en muchas novelas contemporáneas que hurgan en el pasado doloroso de América Latina, prima la memoria individual para llegar así a la colectiva (Fonseca 84; Vanegas Vásquez 164).

En el impulso de Yammara por traer a la memoria el pasado propio y ajeno, desempeñan un papel primordial las percepciones sensoriales, en particular el sentido del oído. En este artículo nuestro propósito consiste, precisamente, en reflexionar sobre la funcionalidad de los recursos sensoriales en El ruido, con énfasis en las modalidades de la audición. Argüimos que las sensaciones auditivas en contraste y diálogo con las visuales están estrechamente vinculadas a la inquietud central de la novela, el difícil y desgarrador rescate del pasado. No solo las imágenes visuales sino también los ruidos, los sonidos y los silencios son desencadenantes y catalizadores centrales del proceso de memoria. Rebasando esta funcionalidad diegética, la indagación en las experiencias sensoriales, y en particular las auditivas, suscita preguntas sobre los modos de representación: ¿cómo se puede hacer que suene un texto? ¿cómo se expresa un sonido? ¿Es posible describir 'el ruido de las cosas al caer'? A la vez, el énfasis en lo auditivo problematiza los modos de comunicación. La reivindicación y la reinscripción de la oralidad mediante remisiones auditivas en un texto escrito remite al debate sobre el fonocentrismo/logocentrismo en la ciudad "letrada" latinoamericana (Marcone 117-162). Al fin y al cabo,

citarse la edición de Karim Benmiloud, Juan Gabriel Vásquez. Une archéologie du passé colombien récent (Presses Universitaires de Rennes, Rennes, 2017), la primera recopilación de artículos dedicada exclusivamente al autor colombiano, así como las consideraciones de Gustavo Guerrero en Paisajes en movimiento (Eterna Cadencia, Buenos Aires, 2018). 
la reflexión sobre las percepciones conduce a que el lector se vea incitado a participar activamente. A este respecto propondremos que el billar, motivo presente al inicio y hacia el final de la novela, funciona como metáfora de una poética que pone en primer plano la interacción con el lector. Por tanto, lejos de tratarse de un juego unívoco e inocuo, el diálogo al que nos invita El ruido mediante su sinfonía de sensaciones, sonidos y silencios resulta ser para el lector un "dañino ejercicio de la memoria" (Vásquez, El ruido 14) 2 .

Para articular nuestro análisis nos basaremos en las teorías de los llamados sound studies, que se inspiran en las discusiones filosóficas respecto a la importancia del oído animadas por pensadores tales como Jean-Luc Nancy (2002) o Peter Sloterdijk (2002). Entre los ejes de discusión de este campo de estudios tres aproximaciones guiarán nuestras reflexiones. Primero, muchos investigadores han indagado en la relación entre la audición y las demás percepciones sensoriales. Como en nuestra sociedad de la imagen es sobre todo la vista la que entra en competencia con el oído (Sterne 7; Dufrenne; Schafer 101), empezaremos nuestro análisis destacando la importancia de la memoria auditiva en combinación y en contraste con la visual. Un segundo punto de interés en los sound studies son las diferentes formas de expresión acústica y de percepción auditiva (Bijsterveld; Pinch). Siguiendo la distinción entre, por una parte, expresiones sonoras de tipo animal, humano y mecánico $\mathrm{y}$, por otra, entre ruidos desagradables y sonidos suaves, trataremos de mostrar que en la novela de Vásquez tanto los ruidos como los sonidos fomentan el proceso de memoria. Los ruidos, sobre todo los de índole mecánica, como por ejemplo la grabación de la caja negra, juegan un papel clave para poner en marcha la indagación concreta en el pasado; en cambio, los sonidos y la sonoridad, tanto en la prosa de El ruido como en las referencias intertextuales, refuerzan el efecto ecoico, la continuidad entre pasado y presente. El tercer enfoque lo constituye la tensión entre el ruido y su opuesto: el silencio. En su tesis de doctorado, Dauncey divide los múltiples usos del silencio en la literatura contemporánea en dos grandes grupos, a saber los silencios sociales en relación con la voz callada de las minorías y los silencios ontológicos que suscitan cuestiones de índole epistemológica. En nuestro análisis de El ruido nos concentraremos en el segundo tipo de silencios, ya que tanto la esporádica mudez de los personajes como las incógnitas en la intriga corresponden con una profunda conciencia de los límites del conocimiento 
y del lenguaje, especialmente cuando de acercarse al pasado se trata. Estos tres ejes nos permitirán ilustrar las dificultades de representación y mostrar la tensión entre la oralidad y la escritura dentro de los modos de comunicación.

\section{LAS PERCEPCIONES SENSORIALES: LA INTERACCIÓN ENTRE LO AUDITIVO Y LO VISUAL}

La importancia de las sensaciones y sus asociaciones recíprocas es una de las características más notorias de $E l$ ruido ${ }^{3}$. Pensemos, por ejemplo, en las sensaciones táctiles que Yammara logra transmitirnos con sus descripciones del frío, el calor y el sudor. Aunque se llevan al extremo en el personaje de Aura, la "enferma de sinestesia" para quien "la casa de una amiga olía a dolor de cabeza" o "un dolor de cabeza podía perfectamente saber a helado de guanábana" (36), queda claro que el propio narrador tiene los sentidos igual de agudos y compatibles. Por muy presentes que estén las demás sensaciones diseminadas por la novela, las que se destacan son las percepciones auditiva y visual. Desde el paratexto son sugeridas las dos vertientes. El título concede el protagonismo a lo auditivo, el ruido de la caída (aunque no especificado), mientras que el impacto de lo visual ("al caer") resulta menguado por la ausencia de un referente claro ("las cosas"). El hincapié en la palabra comodín por excelencia "cosa" anuncia las dificultades de representación e invita al lector a figurarse referentes precisos. Solo podemos adivinar qué es lo que cae y de qué tipo de ruidos se podría tratar, a diferencia de lo que pasa en el booktráiler para promocionar el libro ${ }^{4}$. La imagen de la portada (al menos en

3 La importancia concedida a las sensaciones la comparte Vásquez con dos de sus grandes ejemplos, Marcel Proust y Joseph Conrad. Vásquez reconoce su deuda con el autor francés en el ensayo 'Ethique et poétique de Marcel Proust' (Nouvelle Revue Française 604-605 (2013): 54-60). La influencia de Conrad fue sobre todo importante en sus primeras novelas, en particular Historia secreta de Costaguana. En ensayos y entrevistas de esa época Vásquez solía citar el célebre prólogo a The Nigger of Narcissus en que Conrad expone sus aspiraciones estéticas: "My task which I am trying to achieve is, by the power of the written word, to make you hear, to make you feel - it is, before all, to make you see" (x).

$4 \quad$ En el video primero se van proyectando sintagmas como "caída de aviones", "caída del país", "caída de los sueños", "caída de la familia". Luego, se agregan diferentes sustantivos a la palabra "ruido" que no hacen sino aumentar las claves de lectura: el ruido de la fractura/del miedo/de las armas/de la memoria/ de las bombas/de la pérdida/del amor, que sugieren usos literales y figurados de lo auditivo. Además de estas palabras interesan los efectos 
la edición que manejamos) representa a un jugador con el taco listo para tocar una bola blanca en una mesa roja cuyo choque solo nos podemos imaginar ${ }^{5}$.

Las primeras páginas de la novela continúan el juego del paratexto entre lo visual y lo auditivo. En 2009 las fotos sensacionales de la caza de los hipopótamos escapados del antiguo zoológico de la Hacienda Nápoles de Pablo Escobar llevan a Yammara a recordar a Ricardo Laverde. Como lo sugiere Vanegas Vásquez, las fotos evocadas en el texto operan como una "táctica narrativa en la que se ancla el desencadenamiento de los hechos, además de su capacidad para abrir una ventana oculta de la historia del país" (165). Si bien la percepción visual provoca los recuerdos de su encuentro con Laverde, no tarda en intervenir la memoria auditiva. De hecho, el narrador apunta que el día en que se conocieron, todos los parroquianos de la sala de billar vieron las imágenes del asesinato del político conservador Álvaro Gómez en un televisor mudo:

Primero vimos al periodista que presentaba la noticia desde la puerta de la clínica del Country, después vimos una imagen del Mercedes acribillado - a través de la ventana destrozada se veía el asiento trasero, los restos de cristales, los brochazos de sangre seca-, y, al final, cuando ya los movimientos habían cesado en todas las mesas y se había hecho el silencio y alguien había pedido a gritos que le subieran el volumen al aparato, vimos, encima de las fechas de su nacimiento y de su muerte todavía fresca, la cara en blanco y negro de la víctima (18).

La repetición, en este caso del verbo "ver", en la descripción es una constante del estilo de El ruido que aquí subraya el impacto de las imágenes -por supuesto, no se pueden excluir las resonancias borgesianas de 'El aleph' o garciamarquianas del inicio de El otoño del patriarca-. El reportaje televisivo

acústicos de la banda sonora. El chocar de las bolas, los ruidos de los aviones, los disparos, los gritos de miedo se sobreponen a una lenta melodía tocada en un piano: es intrigante, y a la vez tranquilizante. Todo aquello desemboca en un silencio inquietante.

Las portadas de las ediciones italianas, francesas y españolas, muestran todas una mesa de billar. El escritor nos comentó que al decidir sobre la portada original, la editorial terminó escogiendo el color rojo, aunque el verde esmeralda (el color en la novela) también fue una opción. En cambio, en las ediciones inglesas y neerlandófonas se ha optado por la Plaza de Bolívar con sus palomas revoleteando. Por último, la edición alemana enfoca a un teleférico, con toda probabilidad el funicular de Monserrate, que baja en un ambiente brumoso. 
sobre el asesinato del político va seguido de un comentario sobre el abandono de la Hacienda Nápoles y es entonces cuando vuelve a entrar en juego lo auditivo: recuerda Yammara que fue en ese momento preciso en que oyó hablar por primera vez a Laverde, cuando éste expresó su preocupación por los animales del zoológico. Por tanto, el narrador no solo es un "ocularizador", sino también un "auriculizador", para emplear los términos con los que Schlickers (246) distingue entre las dos maneras de percibir. En la novela abundan ambas modalidades: "ver" y "mirar" aparecen unas 200 veces, mientras que "escuchar" y "oír" unas 120 veces.

A lo largo de la novela se multiplican tales momentos en que lo auditivo y lo visual concurren y compiten en el proceso de resucitar y entender el pasado. Así, al escuchar en la grabación de la caja negra las últimas palabras de los pilotos, Yammara confiesa que hubiera preferido no "espiar los últimos segundos de un hombre" (84, nuestra cursiva). Más que en ningún otro fragmento, aquí el narrador realza la escucha como manera de "mirar" hacia atrás:

Yo, en el fondo, no tenía derecho a escuchar esa muerte ... Y sin embargo esos ruidos formaban parte ya de mi memoria auditiva. Desde que la cinta cayó en el silencio, desde que los sonidos de la tragedia cedieron el lugar a la estática, supe que habría preferido no escucharla, y supe al mismo tiempo que mi memoria seguiría escuchándola para siempre ... Las palabras y las voces de los muertos me tragaban como un remolino de río se traga a un animal cansado (84).

La última frase ilustra lo difícil que resulta expresar el efecto que surten las palabras escuchadas: el narrador se ve obligado a recurrir a una comparación visual. Ya apuntó Chapman que "the range of vocabulary directly connected with sounds is limited, and the desired auditory effect may be conveyed through synaesthesia - borrowing language normally associated with one of the other senses" (29) ${ }^{6}$. El que los sonidos sean hechos "visibles" textualiza la contienda entre lo visual y lo auditivo y subraya la mediatez en el proceso de reconstrucción del pasado.

Aun así, al acentuar la memoria auditiva al lado de la visual, la novela de Vásquez entra en diálogo con las preguntas planteadas por la filosofía

\footnotetext{
"Ya que la gama léxica directamente conectada con los sonidos es reducida, el deseado efecto auditivo puede expresarse mediante la sinestesia, esto es, el préstamo de palabras que normalmente se asocian con uno de los otros sentidos" (Nuestra traducción).
} 
empirista, la neuropsicología y la psicología cognitiva que indagan en las aptitudes sensoriales del ser humano. Advierte Mitchell (16) que en los estudios sobre el funcionamiento de los procesos cognitivos, los paradigmas visual y pictórico suelen ocupar una posición privilegiada. Al menguar esa hegemonía, El ruido ataca la tiranía visual, el ocularcentrismo, una postura también articulada por pensadores como Martin Jay (1994) y Jean-Luc Nancy (2002). Según Yammara no es suficiente the mind's eye, expresión acuñada por Shakespeare en Hamlet y citada en El ruido: "En el ojo de la mente, se dice a veces. El ojo de mi mente trató de ver a Aura antes de la muerte de Ricardo Laverde; trató de verme a mí mismo; pero fue en vano" (136). De manera significativa, en la escucha simultánea de las dos grabaciones en la Casa de Poesía Silva, un fragmento clave sobre el que volveremos más adelante, la vista queda relegada al segundo plano: Laverde escucha llorando la grabación fatídica de la caja negra, de modo que se le obnubila la vista, mientras que Yammara termina cerrando los ojos para recluirse en los deleites sonoros de la poesía de Silva. Como lo muestran los ejemplos mencionados, la visualización de las imágenes mentales no basta para hurgar en el pasado. En El ruido, todas las sensaciones, y en particular la interacción entre la percepción auditiva y la visual, contribuyen a la reconstrucción del pasado y al conocimiento ontológico.

\section{RUIDOS, SONIDOS Y SONORIDAD MUSICAL}

En su libro titulado Mechanical Sound (2008), Karin Bijsterveld subraya la importancia de los sonidos mecánicos que caracterizan el entorno moderno y urbano. Al estar ambientada la novela de Vásquez en la Bogotá de finales del siglo, proliferan unos ruidos y sonidos no naturales que en la mayoría de los casos no acarician el oído ni tampoco traen buenas noticias. Es más, en la evocación del pasado predominan los ruidos que Bijsterveld califica de siniestros: gritos de miedo, ráfagas de metralleta, alarmas y disparos. Pero la modernidad no solo generó ruidos y sonidos nuevos, sino también toda una serie de aparatos que supuestamente los reproducen: la grabadora, la radio, la televisión, el teléfono y el contestador multiplican la posibilidad de reproducir voces, sonidos y ruidos. En esas reproducciones, el sonido original siempre se ve influenciado o hasta distorsionado por diferentes factores, como por ejemplo el tipo de micrófono usado. Por lo mismo, señala Altman (229), las grabaciones no reproducen el sonido, sino que lo representan. Aunque 
solo sean representaciones sonoras que traicionan su supuesta alta fidelidad, inciden de manera reveladora en la reconstrucción del pasado y hacen avanzar el relato ${ }^{7}$. Pensemos en la ya citada noticia en televisión sobre la Hacienda Nápoles, en la invitación de Maya, la hija de Laverde, en el contestador de Yammara y, por supuesto, en el fatídico casete de la caja negra, sobre el que el narrador observa: "Y así resulta que ese aparato, inventado como memoria electrónica de los aviones, ha acabado por convertirse en parte definitiva de mi memoria" (85). Todos estos medios electrónicos que se podrían considerar estilos directos en sentido amplio, aspiran a un efecto auditivo, sin dejar de marcar la distancia con la experiencia física de la escucha. Cabe agregar que en El ruido, los estilos directos en sentido estricto, aunque minoritarios, casi siempre son altamente reveladores para la intriga. Solo aparecen en momentos clave: en las conversaciones/disputas con Aura y en las confesiones de un trauma, momentos en que el diálogo se convierte en monólogo, por ejemplo, en el caso de Laverde (su pasado como piloto: 28-31) o Barbieri (la explicación sobre la marihuana: 186) o Aura (la relación con sus padres: 37-39).

En la novela, tanto los ruidos siniestros como los aparatos de sonido suelen emitir o prefigurar mensajes y eventos dramáticos. Como tal no solo contrastan con las esporádicas menciones de sonidos naturales más suaves y sosegadores: el latido del corazón de Leticia, la hija de Yammara, los susurros usados en contextos íntimos familiares, algún aislado sonido bucólico en casa de Maya. Contrapuntean, ante todo, con el tono sereno y poético de la voz narradora, con razón uno de los aspectos de El ruido que más han alabado los reseñadores y colegas escritores. Así, en una columna titulada, de manera significativa, 'La música del ruido', Héctor Abad Faciolince elogió la "voz afinadísima, musical, una voz compleja y serena a pesar de lo atormentada" (n.p.); de modo parecido, Rodrigo Fresán exaltó la fuerza de las comparaciones y Edmund White enalteció la poesía fría y amarga de la prosa vasquiana (n.p.); y el propio autor subrayó la importancia que concede a la sonoridad de la prosa ("Un fósforo en la oscuridad" 211-12). Para dar

En lo que atañe a la idea de la falacia de las máquinas reproductoras de sonido nos inspiramos en lo observado por McEnaney (371-386). En un contexto de literatura latinoamericana una grabación no puede sino asociarse al género del testimonio y todas las discusiones que originó sobre su presumida veracidad. Aunque Vásquez usa la grabadora en otro contexto se cuestiona también su efecto de realidad. Véanse también los comentarios de Vanegas Vásquez (164) respecto a la incorporación de dispositivos mnemotécnicos como la grabación (y las fotos) para evidenciar lo ocurrido. 
una idea de la sonoridad poética con que se evoca un mundo rudo y ruidoso basta con resaltar un solo fragmento representativo, la escena del atentado contra Laverde en que Yammara también resulta herido:

Entonces vi la moto bajando a la calzada con un corcoveo de caballo, la vi acelerar para acercarse como un turista que busca una dirección, $\mathrm{y}$ en el preciso momento en que tomé a Laverde del brazo, en que mi mano se aferró a la manga de su abrigo a la altura del codo izquierdo, vi las cabezas sin rostro que nos miraban y la pistola que se alargaba hacia nosotros tan natural como una prótesis metálica, y vi los dos fogonazos, y oí los estallidos y sentí la brusca remoción del aire (49).

No solo llama la atención, una vez más, la insistencia en las sensaciones, sino también la abundancia de figuras retóricas: las metáforas y símiles, el polisíndeton, la repetición que, como ya señalamos, es una figura recurrente en la novela que se construye casi siempre con verbos de percepción sensorial -como aquí- o cognitivos -recordar, saber, etc.-. Y es precisamente este estilo sonoro y sensorial el que sirve para transmitirnos la conmoción causada por la acción ruidosa y siniestra: movimientos bruscos, pistola, fogonazos, estallidos.

Dentro de los procedimientos que intensifican la sonoridad poética de la novela salta a la vista el juego de ecos y repeticiones. No es una casualidad que en el modelo neuropsicológico de Atkinson y Shiffrin (1968) la memoria auditiva también se llame memoria ecoica, en contraste con la memoria visual o icónica. Los ecos permean el estilo vasquiano: a lo largo del relato resuenan varias palabras, formulaciones y frases ${ }^{8}$. Pensemos, por ejemplo, en las palabras como "miedo" o "culpa" que acechan al narrador, en el refrán "Algo habrá hecho" puesto en boca de varios personajes (22, hombre del billar; 55, padre de Yammara; 75, Consuelo; 239, Maya) o en la muletilla garciamarquiana de "muchos años después", sintomática del ambiguo diálogo que establece Vásquez con su ilustre compatriota (Bogoya). Este procedimiento de duplicaciones y resonancias a nivel estilístico concierta con los reflejos y repeticiones a nivel de los personajes, de manera que se confunden los sucesos en sus vidas. Así,

\footnotetext{
En una entrevista con Javier Marías ("Los rostros y el tiempo", Letras Libres 31 de enero 2011, https://www.letraslibres.com/mexico/los-rostros-y-el-tiempo-entrevista-javiermarias), Vásquez se detiene en la importancia de las resonancias, las repeticiones de frases enteras en la obra del escritor español. Este recurso también forma parte de la poética del propio Vásquez y se intensifica en Las reputaciones, donde es recurrente la frase retomada de Lewis Carroll: "Es muy pobre la memoria que sólo funciona hacia atrás".
} 
Yammara empieza a identificarse con Ricardo Laverde desde el momento en que caen víctimas del mismo atentado y son yuxtapuestos en la ambulancia "como una sombra junto a otra" (50). En palabras de González González, "uno espejea al otro, en una operación de solapamiento de las huerfanías de ambos" (160). La asociación se extiende a sus familias: el triángulo RicardoElaine-Maya refleja el triángulo Antonio-Aura-Leticia. O pueden citarse, entre otros muchos paralelos y repeticiones, los diferentes accidentes aéreos: el atentado contra el avión de Avianca ordenado por Escobar, el accidente que presencia el padre de Laverde en el show de 1938, el accidente en que muere Elaine. La repetición constituye otra modalidad de la memoria, ya que recordar significa también "semejar a otro": los ecos en la forma y el contenido de la novela parecen reforzar la idea de que el hurgar en el pasado no lleva a la tranquilidad en el presente ni a una revelación de una verdad única, sino que se entrecruzan y se confunden vivencias del pasado y del presente, vidas, situaciones familiares, privadas y públicas.

La dimensión poética se ve reforzada, asimismo, por las resonancias intertextuales ${ }^{9}$. Vásquez intercala versos de José Asunción Silva, León de Greiff y Aurelio Arturo, tres grandes poetas colombianos en cuya obra sobresale la propensión a la sonoridad y la musicalidad ${ }^{10}$. Al citarlos, el escritor reivindica la dimensión auditiva y oral como elemento constituyente de su cultura. En un sentido más amplio, la importancia de la voz y la oralidad en la formación de la nación colombiana ha sido recientemente estudiada por Ochoa Gautier en Aurality. Listening \& Knowledge in Nineteenth-Century Colombia (2014). En El ruido, no en balde los tres poemas citados se caracterizan por su fuerza sonora: las eses susurrantes en el caso del conocido verso "Y eran una sola

\footnotetext{
Nos limitaremos a las remisiones a la poesía. Hay también referencias intertextuales (o, si se prefiere, intermediales) a canciones. A nuestro modo de ver, desempeñan más bien un papel de contextualización en el tiempo histórico. Así, "Who needs the Peace Corps", una canción de 1968 de Frank Zappa, cuyo primer verso da el título al quinto capítulo y es citada varias veces en él, presenta una crítica del altruismo gratuito de los hippies en los Cuerpos de Paz, que viene a ser una forma de escape parecida a la adicción a las drogas.

10 La música es un elemento central en el modernista Silva, el centenario de cuya muerte fue conmemorado precisamente en 1996. En lo que se refiere a de Greiff, Jorge Zalamea escribe: "Yo no tengo memoria ni conocimiento de otro poeta que, como León de Greiff, haya sabido concertar una más pertinente, equitativa y competitiva alianza entre música y poesía" (xiii). Y sobre Aurelio Arturo escribe William Ospina: "Su más notable virtud es la música" (35). Para más comentarios sobre la intertextualidad con los tres poetas, véanse las observaciones de Aníbal González (484-87).
} 
sombra larga" (47) del 'Nocturno' de Silva, las agresivas oclusivas de las palabras arcaicas en "Quiero catar silencio/ non curo de compaña" (55) de 'Admonición a los impertinentes' de de Greiff, y la dureza de las consonantes en "Y ardían desplomándose los muros de mi sueño,/ ¡tal como se desploma gritando una ciudad!' (256) de 'Ciudad de sueño' de Arturo, citado en epígrafe y ampliado en las últimas páginas de la novela.

Según Gaitán Bayona, en El ruido ni esos "intertextos resultan a salvo, como si la belleza estética no fuera redención sino otra zona más de devastación, miseria y muerte" (n.p.). En efecto, la apocalíptica destrucción de la ciudad del poema de Arturo se torna espejo del derrumbe de Yammara y, por extensión, de toda una sociedad secuestrada por la narcoviolencia. De manera parecida, la soledad devastadora de los versos de de Greiff refleja la desolación de Yammara. Quizá la poesía no ofrezca redención, pero sí refugio y reflejo: en los versos de de Greiff, Yammara reconoce su inexplicable deseo de soledad (55). La función de la poesía como refugio queda aún más clara en el caso de la referencia a Silva. En la Casa de Poesía, Yammara ve cómo Laverde rompe a llorar al escuchar su grabación enigmática, pero en vez de consolar a su amigo, el narrador prefiere refugiarse en "la seguridad y el silencio" de su propia grabación: "La melancolía del poema de Silva me entristecía sin arriesgarme. Pensé que la tristeza de Laverde estaba llena de riesgos" (46). Poco después Yammara vuelve a describir la poesía como un espacio silencioso y solitario donde cobijarse de los ruidos y riesgos de la realidad:

En mi cabeza, y sólo en mi cabeza, Silva decía $Y$ eran una sola sombra larga. En mi mundo sin ruido, donde todo estaba lleno de la voz del barítono y de las palabras de Silva y del piano decadente que las envolvía, pasó un tiempo que se alarga en mi memoria. Quienes oyen poesía saben que eso puede suceder, el tiempo marcado por los versos como por un metrónomo y a la vez estirándose y dispersándose y confundiéndonos como el tiempo de los sueños (47).

La idea de la poesía como oposición al violento y vocinglero mundo de afuera concuerda con la tesis que defiende Susan Stewart, según quien la tarea de la poesía consiste en contrarrestar la oscuridad y el olvido. En una realidad arrasadora e incomprensible, la poesía transmite sensaciones y mensajes que pueden generar reconocimiento intersubjetivo, tender puentes entre la experiencia individual y social (2). En muchos momentos, la dimensión poética de El ruido -la sonoridad y la fuerza retórica de la prosa, el juego de ecos- responde a las mismas convicciones y aspira a efectos parecidos. Es 
como si la sonoridad de la poesía, género más cercano a la oralidad desde sus orígenes, sirviera mejor para abordar el pasado. Sin embargo, como veremos en el próximo apartado, también hay momentos en que brotan las dudas sobre la capacidad comunicativa del lenguaje, momentos en que las palabras se quedan cortas y ni siquiera los 'silencios' de la poesía ofrecen auxilio: momentos en que el silencio se hace trágico y total.

\section{RUIDO Y SILENCIO}

En Silence (1971), el compositor John Cage recuerda que el sonido coexiste necesariamente con su contrario, el silencio. Al igual que en la música, en la literatura los usos y efectos del silencio pueden ser múltiples. Como señala Janet Pérez, en una novela el silencio suele manifestarse en primer lugar a nivel de los personajes:

Logically, silence is associated with the ineffable, the inexpressible, the awesome or sacred, horrible or sublime, but also linked to such communicable states as guilt, anger, fear, inhibition, desire, embarrassment, confusion, hostility and disbelief, to name but a few. All of these may be conveyed in the narrative or theater by silence on the part of a character or characters at a given moment - the inability or refusal to reply, loss of words, etc. (111) ${ }^{11}$.

En efecto, en El ruido los recuerdos son a veces tan hirientes que los personajes quieren "catar silencio", para retomar la expresión del poema de de Greiff. Así, la visita a las ruinas de la Hacienda Nápoles provoca el silencio en Yammara y Maya:

Pero tal vez lo más extraño de esa tarde es que todo lo que vimos lo vimos en silencio. Nos mirábamos con frecuencia, pero nunca

11 "Lógicamente, el silencio no solo se relaciona con lo inefable, lo inexpresable, lo impresionante o lo sagrado, lo horrible o lo sublime, sino también con estados de ánimo que sí se pueden comunicar, tales como la culpa, la ira, el miedo, la inhibición, el deseo, la vergüenza, la confusión, la hostilidad y la incredulidad, para solo nombrar algunos. En la narración o el teatro todos esos estados pueden expresarse mediante el silencio por parte de uno o más personajes en un momento determinado -la incapacidad de contestar o la negativa a hacerlo, quedarse sin palabras, etc.-" (Nuestra traducción). 
llegamos a hablar más allá de una interjección o un expletivo, quizás porque todo lo que estábamos viendo evocaba para cada uno recuerdos distintos y distintos miedos, y nos parecía una imprudencia o quizás una temeridad ir a meternos en el pasado del otro (236).

De Hollanda también destaca la trascendencia del fragmento, llegando a proponer que "no silêncio que guardam [los personajes] nesse instante, nas lembranças que surgem, e nos medos que voltam e abafam as sensações anteriores, parece se condensar o propósito do romance" (276) ${ }^{12}$. A nuestro modo de ver los adverbios de duda ("tal vez", dos veces "quizás") incluso parecen sugerir que el silencio no solo se debe a los recuerdos y sensaciones dolorosos, sino a la toma de conciencia de que el afán de conocer a fondo el pasado y la intimidad, tanto propia como ajena, está abocado al fracaso. En otras palabras, los silencios a nivel de los personajes, enfatizados por la repetición de "en silencio" que ritma las frases que describen el subsiguiente regreso a la casa de Maya, dejan traslucir incertidumbres epistemológicas y ontológicas. A esa conciencia de los límites del conocimiento corresponden los cabos sueltos en la intriga: no llegamos a saber quién mató a Laverde, ni por qué, y cerramos la novela sin saber si Yammara y Aura llegan a reconciliarse. De manera significativa, El ruido termina con Yammara preguntándose qué haría si Aura volviera a llamar: “¿Guardaría silencio para que ella se diera cuenta de que había sido un error abandonar nuestra vida? ¿O trataría de convencerla, de sostener que juntos nos defenderíamos mejor del mal del mundo, o que el mundo es un lugar demasiado riesgoso para andar por ahí, solos, sin alguien que nos espere en casa, que se preocupe cuando no llegamos y pueda salir a buscarnos?" (259). Como lo sostiene Pérez (119), tales novelas de final abierto incitan a la interacción, pues proyectan un silencio más allá del texto, un silencio inquietante que sólo el lector puede interpretar.

Advierte Dauncey (237) que en muchas novelas el papel ontológico que se otorga al silencio está estrechamente relacionado con la percepción de la deficiencia del lenguaje. Así ocurre en El ruido: las dudas en cuanto al conocimiento conllevan, inevitablemente, dudas en cuanto al lenguaje. La dificultad o imposibilidad de recordar y resucitar las sensaciones es algo que

12 "En el silencio que guardan los personajes en aquel instante, en los recuerdos que surgen, y en los miedos que vuelven y encubren las sensaciones anteriores, parece condensarse el propósito de la novela" (Nuestra traducción). 
viene preocupando a Vásquez desde hace mucho tiempo. Tiene sus raíces en el cuento temprano "Recuperación" (2002), en que el narrador, por cierto también llamado Yammara, dice: "Los olores no se pueden recordar, y cada vez que olemos o que tocamos tocamos y olemos por primera vez, y uno puede decir que sabe a qué huele algo -un pedazo de pan, por ejemplo- pero no puede revivir el olor del pan al decirlo" (161). No obstante, en El ruido, el narrador se obstina en intentar revivir las sensaciones del pasado. Concentrándonos en los ruidos y sonidos, a pesar de la supuesta reproductibilidad mecánica, concretada en la grabación, Yammara no llega a reconstruirlo todo. Conforme con la conocida idea de Benjamin, el aura de los ruidos y sonidos del pasado parece escapársele, tal como se le escurre su propia Aura. En varias ocasiones, la función referencial que de por sí caracteriza el ruido es desvirtuada y cuestionada. El ejemplo más llamativo lo constituye el momento en que el narrador intenta describir el ruido final de la grabación, el único fragmento en que se retoma el título de la novela:

Hay un grito entrecortado, o algo que se parece a un grito. Hay un ruido que no logro, que nunca he logrado identificar: un ruido que no es humano o es más que humano, el ruido de las vidas que se extinguen pero también el ruido de los materiales que se rompen. Es el ruido de las cosas al caer desde la altura, un ruido interrumpido y por lo mismo eterno, un ruido que no termina nunca, que sigue sonando en mi cabeza desde esa tarde y no da señales de querer irse, que está para siempre suspendido en mi memoria, colgado en ella como una toalla de su percha.

Ese ruido es lo último que se oye en la cabina del vuelo 956.

Suena el ruido, y entonces se interrumpe la grabación (83-4).

Por muchos rótulos que se puedan inventar para los diferentes tipos de ruido (humano, mecánico, natural), el ruido crucial de la novela no puede ser encasillado ni nombrado. Se caracteriza por paradojas y un "o" no disyuntivo. A pesar de la obsesiva repetición de la palabra "ruido", o precisamente a causa de ella, Yammara no llega a darnos una idea muy clara de cómo suena. Pese al uso de un demostrativo ("ese ruido") y de un artículo determinado ("el ruido") no se determina nada al final de la cita. El símil visual (aquí también) desconcierta aún más: el ruido cuelga como una toalla en su percha. El que las dos últimas frases constituyan un párrafo en sí, que estén separadas por un sangrado y vayan seguidos de un blanco, tal vez sugiera el silencio, que solo es descrito mediante una perífrasis: "se interrumpe la grabación" (84). 
El fragmento analizado muestra hasta qué punto El ruido oscila entre la ya mencionada concepción poética de Stewart, quien conserva la fe en el lenguaje como vehículo de las sensaciones y el conocimiento, y la visión más escéptica de James Longenbach, quien arguye que el conocimiento que nos transmite la poesía es fundamentalmente complejo y contradictorio. Si se mira bien, el poético fragmento crucial de El ruido sufre de la paradoja a la que alude Longenbach en The Resistance to Poetry: "Especially when it has something urgent to say, a poem's power inheres less in its conclusions than in its propensity to resist them, demonstrating their inadequacy while moving inevitably toward them" $(10)^{13}$. Es exactamente lo que ocurre en la cita. La descripción se vuelve más vaga a medida que avanza: de "un grito entrecortado" llegamos a "un ruido interrumpido y por lo mismo eterno". El ruido crucial de la novela se resiste a ser descrito, y es como si el narrador fuera dándose cuenta de ello mientras más lo intenta. Solo puede constatar la derrota y el fracaso, no llega a representar nada.

'El ruido de las cosas al caer' resulta ser algo inasible que rebasa lo que se puede captar en palabras, de manera que desemboca en lo indecible, lo indescriptible, el silencio. El lenguaje como herramienta se queda corto, ya que no llega a dar cuenta de los ruidos. Por eso, Vásquez nos deja cabos sueltos y silencios, es consciente de los límites del saber y del lenguaje que lo expresa: la reconstrucción del pasado queda truncada. Lo escribe Luis Villoro en La significación del silencio: "El silencio no puede ampliar el ámbito del mundo que el hombre puede proyectar en un lenguaje objetivo. Solo puede mostrar los límites de ese lenguaje y la existencia de algo que por todas partes lo rebasa" (12). Las observaciones de Colodro refuerzan aún esta idea: "El silencio manifiesta a su vez ausencia, aquello que al no ser precisado en el habla, permanece olvidado en las profundidades implícitas de lo explícito" (18). Y sin embargo, contrariamente a la famosa divisa wittgensteiniana "De lo que no se puede hablar, hay que callar", Vásquez se niega al silencio. Como vimos, aun plenamente consciente de la deficiencia del lenguaje, no puede dejar de tratar de describir lo indescriptible.

13 "Especialmente cuando tiene algo urgente que decir, la fuerza de un poema, más que en sus conclusiones, radica en su propensión a resistirlas, demostrando su insuficiencia al tiempo que inevitablemente se mueve hacia ellas" (Nuestra traducción). 


\section{CONCLUSIÓN}

$\mathrm{Al}$ analizar las percepciones auditivas nos hemos topado con sus limitaciones y sus posibilidades. Las referencias auditivas permiten abordar el pasado de forma distinta y complementaria a las visuales, aportan un alto nivel de sonoridad a la novela como manera de bregar con el pasado lastimoso y tantean los límites de lo decible y lo rescatable. Además, plantean una serie de interrogantes sobre el cómo decir, el qué decir, el por qué (no) decir. En varios momentos del análisis hemos subrayado los problemas que implica la representación de lo auditivo. Su mediatez infranqueable en un texto escrito solo puede llevar a una nostalgia por el sonido de las palabras (¿son-ido?) y por la oralidad. Es precisamente allí donde reside la fuerza de la novela. A diferencia de una película en la que escucharíamos los ruidos y se visualizarían las cosas al caer, las manifestaciones auditivas en la novela contribuyen sustancialmente a expresar de un modo mucho más ambiguo la lucha y el lento proceso de reconstrucción del pasado.

Enfrentado a esta novela llena de resonancias, le incumbe al lector un papel de participación activa. Nos parece que el motivo del billar podría simbolizarlo. No es una casualidad que el billar aparezca en lugares estratégicos de la novela. Tras anunciarse en la portada, en el primer capítulo desempeña un papel protagónico, ya que constituye el motivo del acercamiento entre Yammara y Laverde. No por casualidad una de las descripciones hace resonar el endecasílabo del título: "El ruido de las bolas al chocar, de las cuentas de madera en los cables, de las tizas azules al frotarse sobre las puntas de cuero viejo, todo eso constituía su vida pública [de Laverde]" (23; nuestro énfasis). Luego, el billar reaparece a modo de guiño en el tercer capítulo en una descripción del apartamento de Yammara y Aura, cuyo único cuadro representa a "unos billaristas de Saturnino Ramírez que juegan ... con gafas oscuras" $(95)^{14}$. El billar se asoma una última vez al final de la novela, cuando Yammara recuerda la visita con Maya a la Hacienda Nápoles de Escobar:

14 Remite como resonancia visual a una de las centenares de escenas de billares del artista colombiano Saturnino Ramírez (1946-2002), quien siempre pinta a seres volcados hacia la introspección. Conjeturamos que el cuadro evocado pertenece a la colección personal del autor, ya que en su entrevista con Vásquez en Barcelona el periodista Winston Manrique Sabogal percibe en el comedor un cuadro "que parece un Hopper con una escena y un ambiente esenciales en el libro", y comenta al final: "De cerca el Hopper no es Hopper, es un Saturnino Ramírez, un colombiano especializado en el mundo del billar" (n.p.). 
"Vimos las mesas de billar que inexplicablemente nadie se había llevado en seis años" (235).

Según Aníbal González, la mesa de billar "y el juego que en ella se juega, con sus trayectorias, choques y carambolas, es otro símbolo pleno de sugerencias en torno a la función de la casualidad y su reverso, la causalidad, en el contexto tanto de la novela como del 'mundo real"' (483). En un sentido más amplio, el juego del billar en el que intervienen el azar -la indeterminación- y el cálculo podría ser una metáfora de la poética de Vásquez, de la interacción a la que aspira, de los riesgos que corre el lector al aceptar la partida. De hecho, nos inspiramos en las interpretaciones del rudimentario antecesor de la mesa de billar, la mesa de trucos, en el prólogo a las Novelas ejemplares de Cervantes. A este respecto, Michael Scham comentó:

Critics have held this billiards table up as an emblem of Cervantes' art. It has been compared to the "juego de bolos" - a bowling game- in $E l$ coloquio de los perros, as a play of arbitrary chance and indeterminacy; it has been taken as an expression of authorial trickiness and deceit, functioning as a companion image to the allegedly subversive reader described in the prologue to Don Quijote ...; others have seen it as an expression of collaborative, meaningful interaction (3) $)^{15}$.

Vásquez ha dejado constancia de su deuda con Cervantes. En El arte de la distorsión dedica tres ensayos a Cervantes, que estratégicamente se encuentran al inicio, en el medio y al final de la recopilación. En 'Los hijos del licenciado: para una ética del lector' argumenta que el objetivo del escritor de ficciones es conquistar la atención del lector. Aunque su visión acerca del diálogo con el lector se asemeja mucho a la del autor de las Novelas ejemplares hay una diferencia considerable. Cervantes escribió: "Mi intento ha sido poner en la plaza de nuestra república una mesa de trucos, donde cada uno pueda llegar a entretenerse sin daño de barras. Digo, sin daño del alma ni del cuerpo, porque los ejercicios honestos y agradables antes aprovechan que dañan" (30). El lector de El ruido, en cambio, tal vez no salga ileso del "dañino ejercicio de

15 "Los críticos han considerado esa mesa de billar como un emblema del arte de Cervantes. Ha sido comparada al juego de bolos en El coloquio de los perros, como un arbitrario juego de azar e indeterminación; ha sido interpretado como una expresión de la astucia y el engaño por parte del autor, complementando la imagen del supuesto lector subversivo del prólogo del Quijote...; otros la han visto como una expresión de la interacción colaborativa y significativa" (Nuestra traducción). 
la memoria" (14) al que lo invita Vásquez. Al igual que Yammara, que al aceptar una carambola aparentemente inofensiva con Laverde acaba socavando todas sus seguridades, el lector que se deja seducir por la prosa sonora de $E l$ ruido termina inmerso en un mundo de ruidos y silencios desasosegantes, un mundo donde ya nada resulta inequívoco e inquebrantable, ni el conocimiento ni el lenguaje ni el recuerdo.

\section{BIBLIOGRAFÍA}

Abad Faciolince, Héctor. "La música del ruido". El Espectador 6 de mayo 2011. https://www. elespectador.com/opinion/la-musica-del-ruido-columna-275098

Altman, Rick. "Four and a Half Film Fallacies". Ed. Jonathan Sterne. The Sound Studies Reader. London-New York: Routledge (2012): 225-33.

Atkinson, Richard C., Richard M. Shiffrin. "Human Memory: A proposed System and its Control Processes". Eds. Kenneth W. Spence and Janet T. Spence. The Psychology of Learning and Motivation. London: Academic Press, 1968. 89-195.

Bijsterveld, Karin. Mechanical Sound. Technology, Culture, and Public Problems of Noise in the Twentieth Century. Cambridge MA: MIT, 2008.

Cage, John. Silence. Cambridge: MIT Press, 1971.

Cervantes, Miguel de. Novelas ejemplares. Madrid: Edaf, 1982.

Chapman, Raymond. The Treatment of Sounds in Language and Literature. Oxford: Blackwell, 1984.

Colodro, Max. El silencio en la palabra. Aproximaciones a lo innombrable. Santiago de Chile: Cuarto Propio, 2000.

Conrad, Joseph. The Nigger of the Narcissus. A Tale of the Forecastle. New York-Toronto: Doubleday Page and Company, 1921.

Dauncey, Sarah. "The Uses of Silence. A Twentieth-Century Preoccupation in the Light of Fictional Examples, 1900-1950”. Tesis doctoral. University of Warwick, 2003.

De Hollanda Cavalcanti, Diogo. "O resgate de uma experiência esvaziada: El ruido de las cosas al caer e a ficção sobre o narcotráfico". Alea 18.2 (2016): 266-78.

Díaz Sedano, Álvaro Efrén y Camilo Caicedo Hernández. "El delirante ruido: discursos literarios sobre la violencia en Colombia a finales del siglo XX”. Revista Temas 7 (2013): 205-213.

Dufrenne, Mikel. L'oeil et l'oreille. Paris: Jean-Michel Place, 1987.

Fonseca, Alberto. "Revisitando la hacienda Nápoles: las ruinas del narcotráfico en El ruido de las cosas al caer (2011) de Juan Gabriel Vásquez”. Ed. Cecilia López Badano. Periferias de la narcocracia. Ensayos sobre narrativas contemporáneas. Buenos Aires: Corregidor, 2015. 79-91.

Fresán, Rodrigo. "El sonido de un novelista al ascender". Página 12, 12 junio de 2011. https:// www.pagina12.com.ar/diario/suplementos/libros/10-4302-2011-06-12.html 
Gaitán Bayona, Jorge Ladino. “El ruido de las cosas al caer: radiografía del miedo colombiano en la generación del setenta”. La odisea del Quijote 18 de abril 2012. http://quijoterock. blogspot.com/2012/04/el-ruido-de-las-cosas-al-caer.html

Giraldo, Luz Mary. "Del lugar de paso al lugar para el olvido: Bibliowicz, Schwartz, Vásquez". En otro lugar: Migraciones y desplazamientos en la narrativa colombiana contemporánea. Bogotá: Editorial Pontificia Universidad Javeriana, 2008. 115-28.

González, Aníbal. "Entrando en materia: novela, poesía y cultura material en El ruido de las cosas al caer". Cuadernos de literatura XX. 40 (2016): 447-89.

González González, Daniuska. "El presente era un peso y un estorbo. Subjetividades de la huerfanía en la narrativa del colombiano Juan Gabriel Vásquez". Revista Chilena de Literatura 97 (2018): 153-74.

Jay, Martin. Downcast Eyes. The Denigration of Vision in Twentieth-Century French Thought. Berkeley: UP California, 1994.

Longenbach, James. The Resistance to Poetry. Chicago: Chicago UP, 2004.

Marcone, Jorge. La oralidad escrita. Sobre la reivindicación y re-inscripción del discurso oral. Lima: Pontificia Universidad Católica del Perú, 1997.

McEnaney, Tom. "Realismo sonoro y fidelidad literaria: las obras de cinta de Eduardo Costa". Revista de Estudios Hispánicos 50 (2016): 371-86.

Manrique Sabogal, Winston. "Las esquirlas del miedo". El País. Babelia 14 mayo 2011. https://elpais.com/diario/2011/05/14/babelia/1305331935_850215.html

Mitchell, W.J. Thomas. Iconology. Image-Text-Ideology. Chicago: UP Chicago, 1968.

Montoya, Pablo. Novela histórica en Colombia 1988-2008. Entre la pompa y el fracaso. Medellín: Editorial Universidad de Antioquia, 2009. 82-95.

Nancy, Jean-Luc. A l'écoute. Paris: Galilée, 2002.

Ochoa Gautier, Ana María. Aurality. Listening \& Knowledge in Nineteenth-Century Colombia. Durham: Duke UP, 2014.

Ospina, William et al. Cuatro ensayos sobre la poesía de Aurelio Arturo. Bogotá: Fondo Cultural Cafetero, 1989.

Pérez, Janet. "Functions of the Rhetoric of Silence in Contemporary Spanish Literature". South Central Review 1.1/2 (1984): 108-30.

Pérez Sepúlveda, Andrés. "La caída del semblante: violencia política y social en Abril Rojo de Santiago Roncagliolo y El ruido de las cosas al caer de Juan Gabriel Vásquez”. Mundo Nuevo V.12 (2013): 49-67.

Pinch, Trevor and Karin Bijsterveld (eds). Oxford Handbook of Sound Studies. Oxford: Oxford UP, 2012.

Quesada, Catalina. "Vacillements: poétique du désequilibre dans l'oeuvre de Juan Gabriel Vásquez". Eds. Eduardo Ramos-Izquierdo and Marie-Alexandra Barataud. Les espaces des écritures hispaniques et hispano-américaines au XXIe siècle. Limoges: Presses Universitaires de Limoges, 2012. 75-85.

Schafer, R. Murray. "The Soundscape". Ed. Jonathan Sterne. The Sound Studies Reader. London-New York: Routledge, 2012. 95-103. 
Scham, Michael. Lector Ludens. The Representation of Play and Recreation in Cervantes. Toronto: UP of Toronto, 2014.

Schlickers, Sabine. "Focalization, Ocularization and Auricularization in Film and Literature." Eds. Peter Hühn et al. Point of View, Perspective, and Focalization. Modeling Mediation in Narrative. Berlin: De Gruyter, 2009. 243-58.

Semilla Durán, María Angélica. "Le récit cannibale: Historia secreta de Costaguana, de Juan Gabriel Vásquez”. Eds. Michèle Ramond (et al.). Hommage à Milagros Ezquerro. Théorie et fiction. Paris: Rilma 2, 2009. 545-61.

Sloterdijk, Peter. “¿Dónde estamos, cuando escuchamos música?”. El extrañamiento del mundo. Madrid: Ed. Nacional, 2002. 229-53.

Sterne, Jonathan. "Sonic Imaginations". The Sound Studies Reader. London-New York: Routledge, 2012. 1-17.

Stewart, Susan. Poetry and the Fate of the Senses. Chicago: U of Chicago P, 2001.

Vanegas Vásquez, Orfa Kelita. "Fotografía y literatura: dimensión visual de la violencia del narcotráfico en Colombia”. Ed. Cecilia López Badano. Periferias de la narcocracia. Ensayos sobre narrativas contemporáneas. Buenos Aires: Corregidor, 2015. 163-87.

Vásquez, Juan Gabriel. "Recuperación”. Ed. Antonio García. Aaaaaahhh...! Doce relatos eróticos. Bogotá: Planeta, 2002. 151-76. El arte de la distorsión. Madrid: Alfaguara, 2009. El ruido de las cosas al caer. Madrid: Alfaguara, 2011. "Un fósforo en la oscuridad. Conversación con Juan Gabriel Vásquez". Entrevista por Rita De Maeseneer y Jasper Vervaeke. Confluencia 28. 2 (2013): 209-16. "Éthique et poétique de Marcel Proust". Nouvelle Revue Française 603-604 (2013): 54-60.

Villoro, Luis. La significación del silencio. México, D.F.: Verdehalago, 1996.

White, Edmund. "Requiem for the Living". Reseña de The Sound of Things Falling, by Juan Gabriel Vásquez. The New York Times 1 agosto 2013. https://www.nytimes.com/2013/08/04/ books/review/the-sound-of-things-falling-by-juan-gabriel-vasquez.html

Zalamea, Jorge. "Prólogo de la primera edición”. León de Greiff. Obras completas. Bogotá: Tercer Mundo, 1975: T.1: ix-xix. 